\title{
Flexi-Living: adaptable property, adaptable housing, transforming lives
}

\author{
I. MacBurnie \\ Department of Architectural Science, Ryerson University, Canada
}

\begin{abstract}
Founded on the interrelated principles of flexibility and choice, Flexi-Living presents an innovative approach towards more affordable and sustainable residential design and development. It is a middle ground solution combining the best of urban and suburban design and development, adapted to an industrialized building process featuring prefabrication, green architecture, and the latest technology in concrete, steel, and glass. Flexi-Living comprises a pioneering environment in which change is embraced rather than eschewed, in which mass production is celebrated rather than masked, and in which homeowners are empowered rather than forced to comply with a set of rigid and unalterable norms and standards. It proposes a range of property types, from small lot to large lot, from narrow and deep to wide and shallow. It envisages both neighbourhoods which are transformable rather than fixed for all time, and districts in which a plot of land may be subdivided and sold for profit. It features a range of housing types, from single-family detached homes to loft-like walk-up condominium apartments. It proposes dwellings that are adaptable rather than inflexible, such that, according to a homeowner's particular desires, a house may be expanded or reduced in size. Flexi-Living is intended for Greenfield sites situated on the edge of major North American cities. However, it is equally applicable to Greyfield and Brownfield redevelopment.

Keywords: housing, affordability, sustainability, flexibility, choice, live-work, property, change, empowerment, urbanism.
\end{abstract}

\section{Contemporary (sub)urbanism}

The three suburban communities sharing the Levittown moniker may never have been esteemed by the architectural, landscape, or planning avant-garde, but they 
proved to be both enormously popular with middle class consumers, and highly influential for subdivision developers. Premised on the mass production and consumption of inexpensive starter homes (exemplified by the slab-on-grade, one and one-half storey bungalow that could be easily expanded horizontally or vertically), the Levittown concept manifested a certain logic in the land-use segregated, baby-boom era that it came to personify. Within a few decades, however, the rapidly rising cost of land, labour, materials, and infrastructure on the edge of major metropolitan areas, coupled with the emergence of a more diverse and fragmented marketplace, conspired to render this one-size-fits-all approach to subdivision development obsolete. In its place, the suburban real estate industry substituted a range of niche-market products, each geared to a specific class segment and comprising a distinct, physically and socially segregated neighbourhood, highlighted by large, single-family detached homes for the more affluent, smaller, "zero-lot line" houses (meaning that the house is set-back from the property line on three sides, while straddling the property line on the fourth) for those somewhat less well off, and townhomes, condominiums, and walk-up apartments for the rest. While on the one hand the contemporary marketplace offers consumers a wider choice of housing, on the other hand it ties consumers' hands. In the contemporary marketplace, the individual dwelling has in the main become inflexible, prevented from changing either because of zoning (houses invariably occupy the maximum coverage), or because of private restrictions originated by the developer and included in the property deed.

This is especially the case in the United States, where the tract-house approach to subdivision development on the edge of major metropolitan areas was, long ago, usurped by the Planned Unit or Common Interest development. In these communities, a once public territory is replaced by a private, at somewhat higher density, one that is distinguished by a comprehensive set of restrictive covenants and highlighted by collective amenities, such as a golf course, an environment in which continuity is valued and change is shunned. In Canada, where in similar locales the single-family house still predominates, the trend has been toward the provision of ever smaller and narrower lots. In the absence of rear lanes, where vehicles can be stored, the front lawn and tree-lined street that are imbedded in the image of suburbia have given way to a concrete and asphalt landscape dominated by automobiles, driveways, and garage doors. For at least several decades, these environments have been lightning rods for a multitude of critics, especially those who decry sprawl. In the vanguard of the assault and in the propagation of alternative models of development has been the New Urbanism.

\section{New urbanism}

Cornell, Ontario represents the latest wave in suburban residential design and development in Canada. Located in the Greater Toronto Area (GTA) suburb of Markham, the project was master-planned by the Florida-based architectural and planning practice headed by Andres Duany and Elizabeth Plater-Zyberk, according to principles of the New Urbanism. The development features a street- 
and-lane pattern of road infrastructure (the Levittown model dispensed with the lane), a "town centre," several parks, and several thousand dwelling units, for the most part consisting of single-family, detached houses. Conceived for the midrange segment of the middle class marketplace, the residential density achieved in Cornell is perhaps fifty percent higher than in conventional, detached-home subdivisions in the GTA. The typical width of a Cornell lot is somewhat narrower than in a conventional neighbourhood. Most dwellings employ a zero-lot line configuration, and setbacks are significantly reduced. The vast majority of dwellings are single-family detached, two- and three-stories in height. Individual properties feature the house and a detached garage, which is situated to the rear of the lot and accessed directly from the back lane. With all garages located to the rear, Cornell features a streetscape free of driveways. A small number of apartments are provided in the development, the bulk located above stores in the mixed-use buildings that comprise the subdivision's centre, with the occasional apartment built above garages situated on the subdivision's alleys.

Cornell asserts that its design goes a long way towards achieving affordability and sustainability. In the main, these are said to be advanced by the "compact" master plan, resulting in increased residential density and decreased infrastructure per capita, by the embrace of a broader and more diverse population, reflected in the provision of a range of housing types, and by the provision of live-work opportunities. Though the argument is seductive, it is, unfortunately, specious.

Consider the matter of affordability. While in the shorter term a smaller lot may be less expensive to purchase in a high land-cost area like the GTA (although the experience of other New Urbanism projects suggests otherwise, as New Urbanism generally results in higher property values, sometimes much higher, than conventional development), in the longer term affordability is contingent on other factors, such as the ability to adapt to changing circumstances. For instance, what happens to the notion of affordability when a homeowner is elderly and living on a fixed income, when he or she becomes unemployed, or when interest rates begin to rise? Affordability in part means the ability to capitalize on an investment, and a lot and house are a homeowner's greatest assets. While a lot and house can be sold in Cornell, lots and houses cannot be capitalized. Why is that the case? Because Cornell lot types and dwelling types, like those of conventional subdivision development, are inflexible, fixed for all time, as if time stood still. Affordability would be enhanced by a homeowner being able to capitalize on their asset through the sale of part of their real property: their land, house, or both. Unlike pre-Levittown subdivision development throughout North America, to which New Urbanism designers are said to have given more than a passing glance, Cornell lots cannot be subdivided and sold. And, unlike the manner by which urbanism unfolded in older neighbourhoods throughout North America, to which New Urbanism designers are said to have paid particular attention, Cornell houses cannot be converted to duplexes or other types of accommodation. In Cornell, only a handful of dwellings have apartment accommodation located above their 
garages, and there are no separately-accessed basement apartments, as is the case throughout the GTA. McGill University researchers have demonstrated that, after land, the most expensive aspect of housing is finishes. Cornell, however, does not offer homeowners the choice between a fully outfitted interior and a shell to be completed through sweat-equity, over time. No effort has been made to reduce the cost of finishes, in part because finishes is one of the most profitable aspects of housing development.

Consider the matter of sustainability. Like so many New Urbanism projects, Cornell occupies a distant Greenfield site whose eco-system was shattered; lacking was a remediation strategy. Cornell advertises itself as a live-work community, but this is achieved by sleight of hand: the work part of the equation is accommodated in a widened hallway or converted bedroom. For most, however, the reality is that they still must commute elsewhere to work, not to mention to shop. Like so many New Urbanism projects, Cornell employs a hierarchical, street-and-lane pattern of road infrastructure, the street component comprising an aesthetic space, the lane component a functional space. As most activities are auto-oriented, the car-clogged rear lane is Cornell's principal civic space, providing back-door entry to the home. Largely a symbolic space, the street is effectively a little-used stage-set. Like so many New Urbanism projects, Cornell housing does not employ energy-saving technologies such as green roofs, photovoltaic cells, bio-filtration systems, or pre-fabricated, recycled, and non-toxic building materials. Accordingly, energy consumption and emissions are about the same as elsewhere. Like so many New Urbanism projects, Cornell offers an exceptionally limited range (two) of housing types: there are no starter homes and no single-floor homes for the elderly; the vast majority of apartments are clustered in a single complex that comprises the town centre. Cornell dwellings can neither be expanded nor reduced in size: residents are expected to move into a different type of accommodation when circumstances warrant. And, like so many New Urbanism projects, Cornell cannot be intensified over time, unlike the manner by which urbanism has unfolded throughout history in older, inner-city neighbourhoods in North America.

At the end of the day, Cornell, like so many New Urbanism projects, is a cleverly packaged real estate development that accomplishes little in terms of affordability or sustainability. It may be the best the marketplace offers, but it leaves much to be desired.

\section{Flexible urbanism}

Outlined below in black, the Mixed-Density Pocket is the cornerstone of a more affordable and sustainable suburban development paradigm known as the Metropolitan Purlieu. Elaborated by this author for Canada Mortgage and Housing Corporation's Centre for Future Studies, the Purlieu was conceived through a collaborative, workshop process (involving architects, planners, academics, suburban real estate developers, municipal officials, housing experts, and representatives from homeowner associations) both as an alternative to the low density, land-use segregated model of residential development which 
predominates on the periphery, and as an alternative to the New Urbanism. The Purlieu comprised a compact, transit-oriented, "green" community of considerably higher density in which mixed-density pockets - consisting of a range of adaptable lot and housing types - were enveloped by rings of increasingly dense and mixed-use structures culminating in mid-rise perimeterblock and point-block towers fronting major thoroughfares. Programmatically, the Purlieu encompassed rather than rejected all categories of development currently located on the periphery - from light industry to Big Box stores re-conceptualizing and re-formulating these in the process.

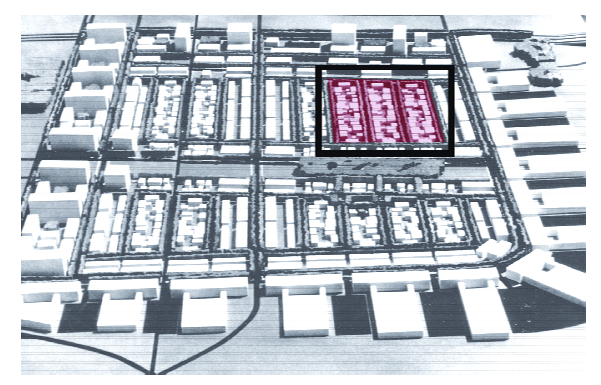

Figure 1: $\quad$ The Metropolitan Purlieu.

\section{Flexi-Living}

The mixed-density pocket is unique in that it alone, among alternative development models for suburbia, embraces change rather than rejects it. Change is the very essence of human existence, yet in the environment where most will live, change is precluded, whether that be in a conventional development, or one designed according to the principles of the New Urbanism. Suburban development models are so commodified that they are conceived for an ideal condition rather than a human condition. Consider a commonplace example. In most conventional and New Urbanism developments, a homeowner not only is unable to alter his or her home's appearance by enlarging a window, but is unable to change even the colour of the front door. Consider a more significant example. Residential lots and housing types are so limited in type and restrictive in scope that not only is it unfeasible to expand a dwelling - for instance, to accommodate a larger kitchen or house a member of an extended family - but there is no room for amenities such as a backyard swimming pool, one of the very icons of the Good Life. In most conventional and New Urbanism projects, individual desires have been subordinated to both a notion of the common good, as advanced either by a homeowners' association or a real estate developer. As one's lifecycle unfolds, it becomes necessary to relocate from one dwelling, neighbourhood, and subdivision to another, and then again, until one retires on a fixed income and then goes through the process yet again. 

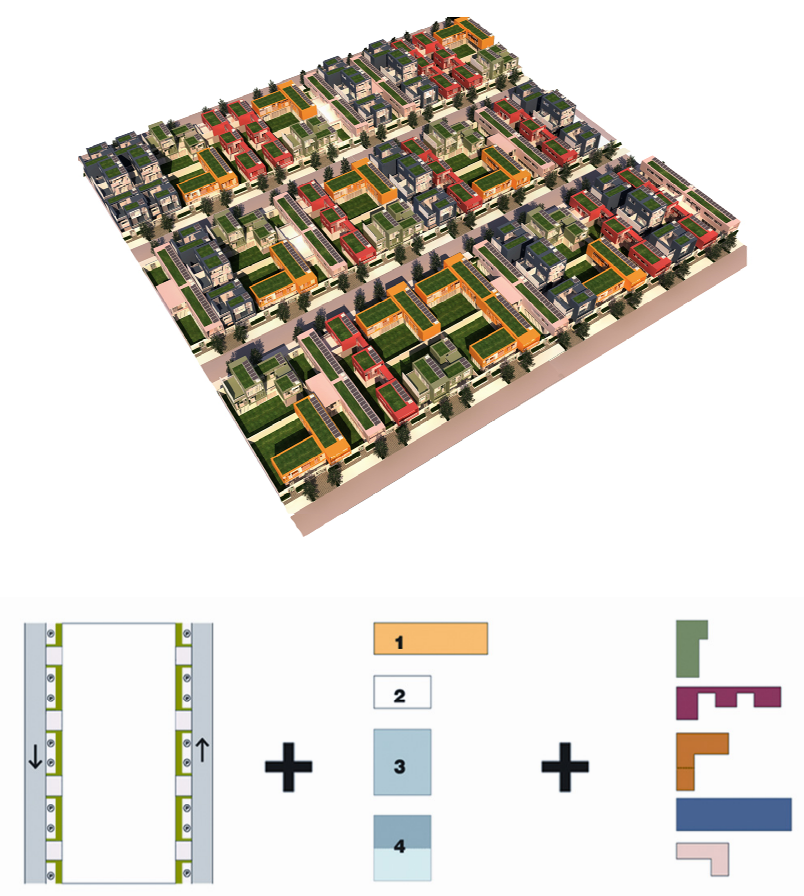

STREET PATTERN

4 LOT TYPES

5 HOUSING TYPES

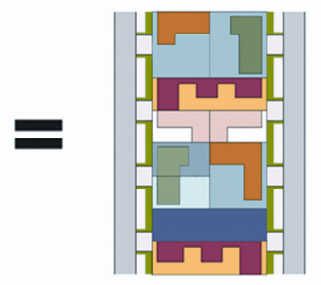

FLEXI-LIVING

Figure 2: The Flexi-Living formula.

The mixed-density pocket was conceived and formulated to embrace change. It comprises an environment in which change has been built-in from the outset, and imbedded in the zoning and private property deeds, a circumstance that neatly sidesteps one of the many impediments to change in the built environment, that of NIMBYism. The pocket is a place where one can live, work, and grow old and retire, without ever having to move. Moreover, it is a place where one's property and home is a manifestation of one's desires and stage in life rather than a representation of the highly edited and packaged vision 
of a real estate brochure. Flexi-Living in the mixed-density pocket responds to the ambitions of real individuals living in the real world. As revealed in the following images, it is a middle ground solution combining the best of urban and suburban design and development, adapted to an industrialized building process featuring prefabrication, green architecture, and the latest technology in concrete, steel, and glass. It comprises a pioneering environment in which mass production is celebrated rather than masked, and in which homeowners are empowered rather than forced to comply with a set of rigid and unalterable norms and standards. Flexi-Living proposes a range of property types, from small lot to large lot, from narrow and deep to wide and shallow. It envisages both neighbourhoods which are transformable rather than fixed for all time, and districts in which a plot of land may be subdivided and sold for profit. It features a range of housing types, from single-family detached homes to loft-like walk-up condominium apartments. It proposes dwellings that are adaptable rather than inflexible, such that, according to a homeowner's particular desires, a house may be expanded or reduced in size.

\section{C-Type: the convertible house}

This 250 square meter, loft-like, live-work, detached dwelling situated on a wide and shallow lot accommodates a dedicated office and separately-accessed, above-ground, in-house apartment. Lot and house have the built-in potential of subdivision: the lot can be readily severed and the dwelling easily modified to generate a free-hold semi-detached, an ideal proposition for the empty-nester. One semi-detached unit is designed to readily accommodate living on one floor, ideal for the elderly.
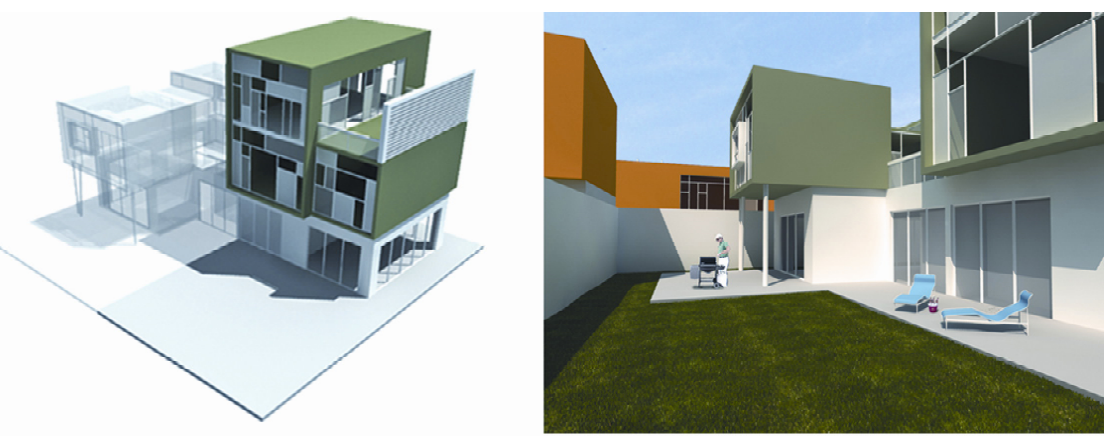

Figure 3.

\section{N-Type: the narrow house}

This 250 square meter, loft-like, live-work, zero-lot line, detached dwelling situated on a narrow and deep lot accommodates a dedicated office and 
separately-accessed apartment located above the garage. Lot and house front onto two streets, facilitating access, the accommodation of amenities such as a swimming pool, and the division of home and apartment.
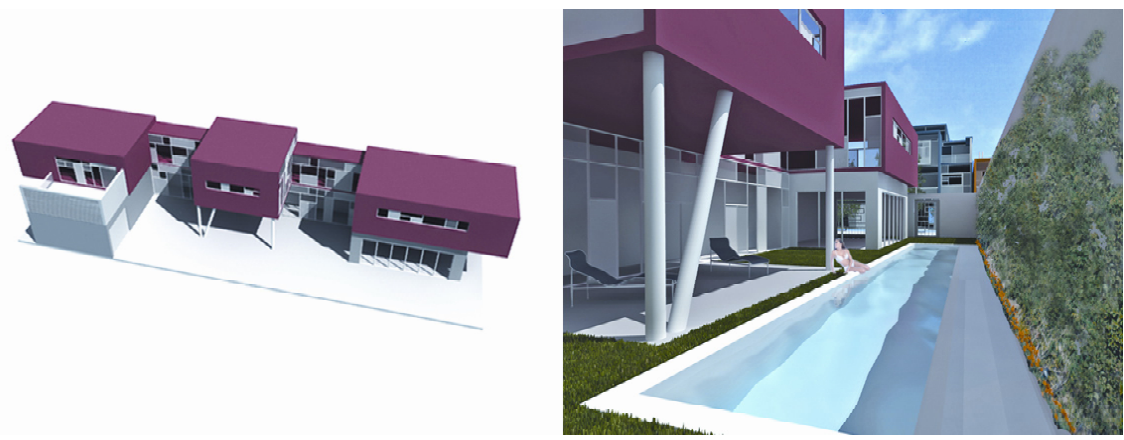

Figure 4.

\section{L-Type: the starter - elderly house}

This 125 square meter, loft-like, live-work, zero-lot line, semi-detached dwelling situated on a narrow and shallow lot accommodates a small, two-story starter house that can be easily modified to accommodate living on one floor. It is ideal for the elderly.
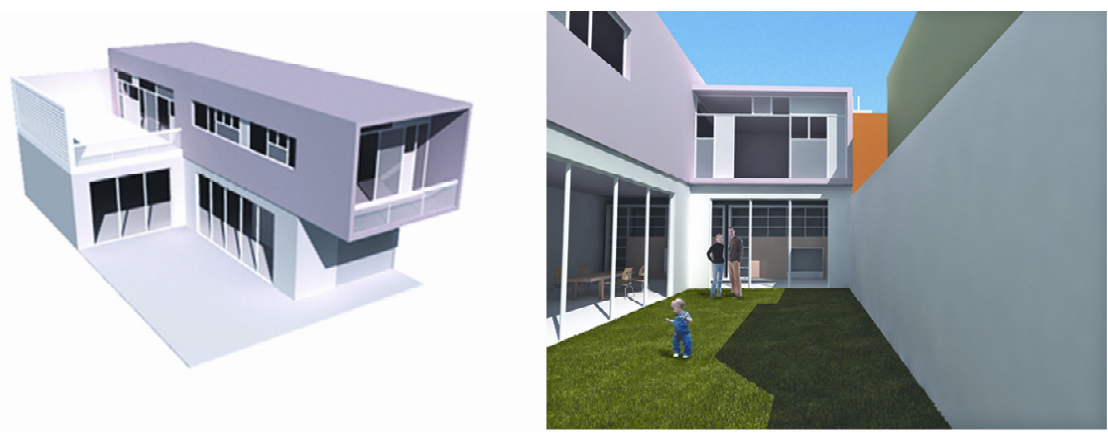

Figure 5.

\section{E-Type: the expandable house}

This 200 square meter, loft-like, live-work, zero-lot line, detached dwelling situated on a wide and shallow lot can be expanded to accommodate a dedicated office and separately accessed, above-ground, in-house apartment. 

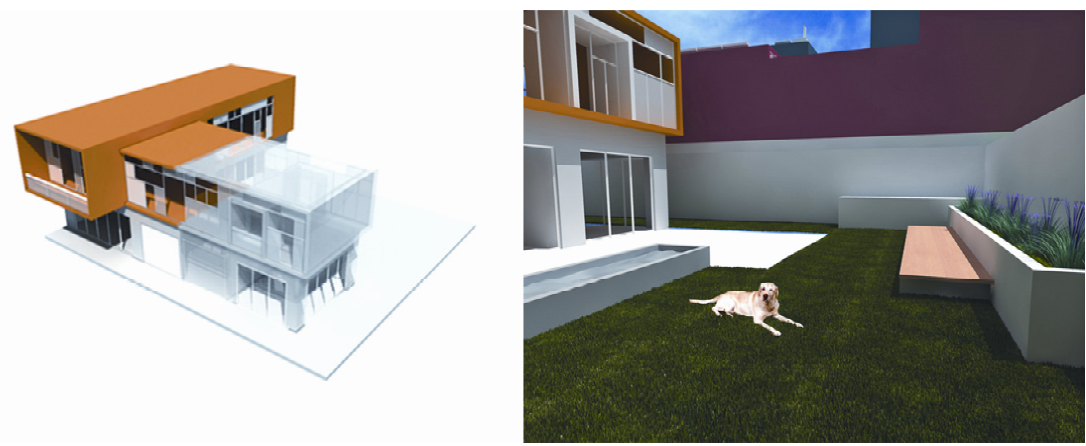

Figure 6.

\section{A-Type: the apartment house}

These 150 square meter, loft-like, live-work, separately accessed, walk-up apartments situated above a ground-oriented parking structure accommodate a dedicated office. Each is a two- or three-story dwelling featuring double-height living spaces and balconies and large terraces oriented for views and maximum privacy.
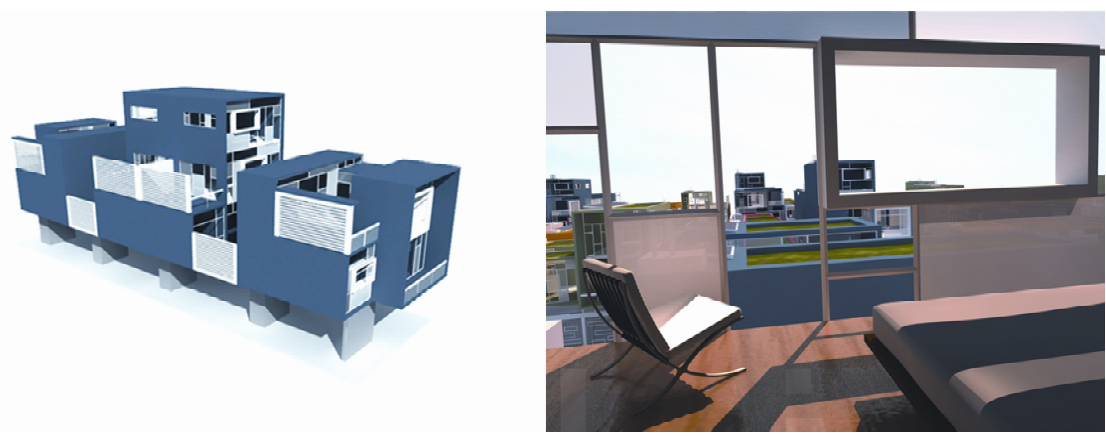

Figure 7.

\section{Conclusion}

The Flexi-Living concept as outlined above is being further articulated and refined in collaboration with federal and provincial housing officials, urban planners, engineers, homebuilders, and subdivision developers. This winter, the concept formed the basis of this author's entry in Archetype, a sustainable housing and urbanism competition sponsored by Toronto's Design Exchange. The submission featured Flexi-Living's concern for managing residential intensification and growth over time. Similar to Flexi-Living, it featured a variety of adaptable house types (referred to as wide, narrow, and tall), two of 
which comprised zero-lot line, detached dwellings, and it emphasized the notion of lot severance. The competition is currently being judged, and the awardwinning schemes will be announced in late April. The scheme awarded first prize will be built as a demonstration project at Kortright, an ecological interpretation center located a few miles north of Toronto.

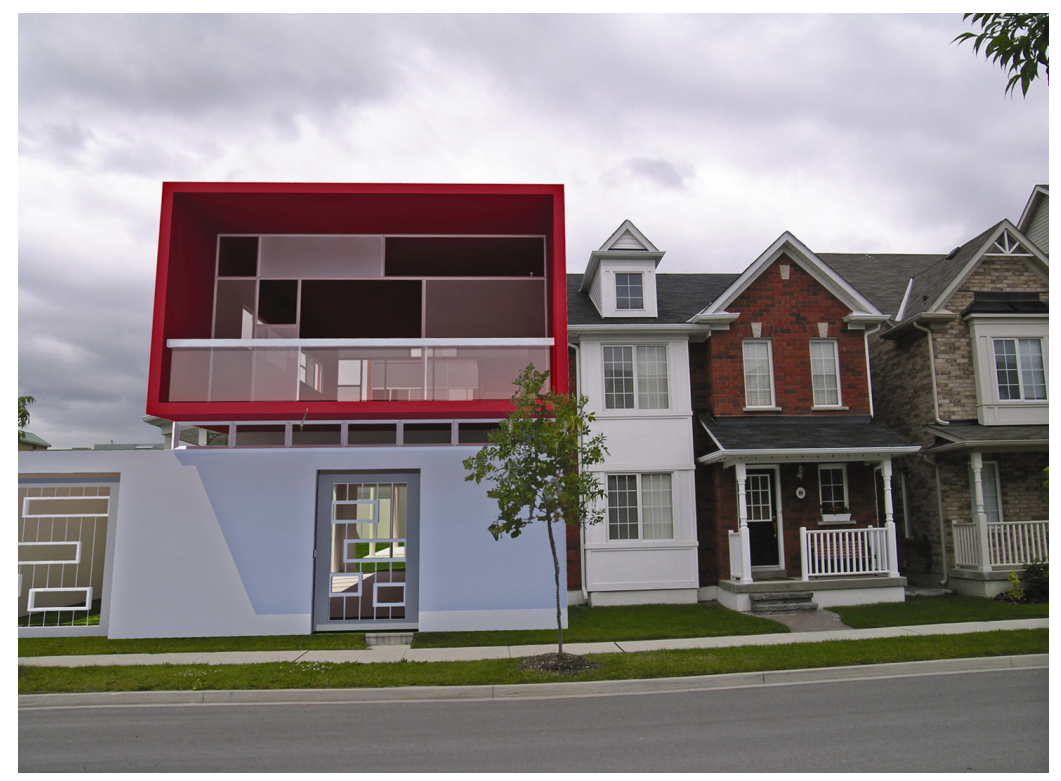

Figure 8.

\section{References}

[1] Friedman, A., Planning the New Suburbia: Flexibility by Design, UBC Press: Vancouver, 2002.

[2] Canadian Housing and Mortgage Corporation., Flex Housing: Homes that Adapt to Life's Changes, C.M.H.C., Canada, 1999.

[3] Friedman, A., The Adaptable House, McGraw-Hill Professional Publishing: New York, 2002.

[4] Friedman, A., The Grow Home, McGill-Queen's University Press: Montreal, 2001. 